\title{
Study on the effect of sublethal concentrations of antimicrobials on the growth and development of probiotic lactobacilli
}

\author{
Ayla Ilyazova $^{1}$, Denica Blazheva $^{1 *}$, Aleksandar Slavchev ${ }^{1 .}$ and Albert Krastanov ${ }^{2}$ \\ ${ }^{1}$ University of Food Technologies, Department of Microbiology, 26 Maritza Blvd., 4002 Plovdiv, Bulgaria \\ ${ }^{2}$ University of Food Technologies, Department of Biotechnology, 26 Maritza Blvd., 4002 Plovdiv, Bulgaria
}

\begin{abstract}
The objective of this study was to investigate the effect of sublethal concentrations of 5 antibiotics (tetracycline, erythromycin, penicillin G, lincomycin, ciprofloxacin) and 2 preservatives (benzoic and sorbic acid) on the growth and development of 8 probiotic Lactobacillus strains. All lactobacilli were subjected to a large range of concentrations, growth curves were plotted and MICs were determined for each antimicrobial. The results showed correlation between the sublethal concentrations and the growth rate of the studied microorganisms. Based on the obtained data two groups of strains could be defined - sensitive and relatively resistant. The first group includes L. bulgaricus S2. L. bulgaricus S4. L. bulgaricus S19 and L. gasseri S20. The most resistant of this group was $L$. gasseri $S 20$. The second group showed more sensitivity and the most affected by the antimicrobials was $L$. bulgaricus $S 28$.
\end{abstract}

\section{Introduction}

The main group of probiotic bacteria in application today are species belonging to the genus Lactobacillus. They have many beneficial effects on the host, which are well documented in reference literature [1,2,3]. A useful trait in a probiotic strain is its resistance to the effect of different antimicrobials, such as antibiotics and preservatives. Benzoic and sorbic acids are commonly used in foods as $\mathrm{pH}$ adjusters and preservatives, preventing the growth of the undesirable microflora [4. 5]. Antibiotics could be ingested in low concentrations with food as residue from the treatment of farm animals [6], or as part of the medical treatment of different diseases. Such antimicrobials potentially disrupt the balance of the intestinal flora, which is linked to various medical conditions - gastrointestinal or infectious diseases, allergies, etc. [7]. The use of probiotic supplements, containing strains, resistant to antimicrobials, could treat dysbacteriosis and prevent its negative health effects.

One the other hand, antibiotic resistance may affect the safety of a probiotic. The antibiotic resistance of a microorganism could be intrinsic, due to a chromosomal mutation or to the acquisition of genetic material through transposons or plasmids [8,9]. According to some authors non-pathogenic bacteria, such as Lactobacillus, could serve as a reservoir of antibiotic resistance genes, which can be transferred to other microorganisms, including human pathogens $[8,10]$. Because of the taxonomic complexity of genus Lactobacillus more data is needed for the antimicrobial resistance of its representatives and the mechanisms behind it.
The objective of this study is to investigate the effect of sublethal concentrations of 5 antibiotics (tetracycline, erythromycin, penicillin G, lincomycin, ciprofloxacin) and 2 preservatives (benzoic and sorbic acid) on the growth and development of 8 probiotic Lactobacillus strains.

\section{Materials and methods}

\subsection{Microorganisms}

Eight probiotic strains from genus Lactobacillus were used: Lactobacillus acidophilus S11. Lactobacillus delbrueckii subsp. bulgaricus S2. Lactobacillus delbrueckii subsp. bulgaricus S4. Lactobacillus delbrueckii subsp. bulgaricus S6. Lactobacillus delbrueckii subsp. bulgaricus S19. Lactobacillus delbrueckii subsp. bulgaricus S28. Lactobacillus gasseri S20 and L. helveticus S3. The strains were isolated from fresh homemade cheese and yogurt. All microorganisms were cultivated in MRS broth (Oxoid, UK) and stored as $15 \%(\mathrm{w} / \mathrm{v})$ glycerol stock cultures at $-30^{\circ} \mathrm{C}$.

\subsection{Preparation of active bacterial culture}

Active bacterial cultures were prepared by inoculation of $1 \mathrm{ml}$ MRS broth (Oxoid, UK) with $50 \mu 1$ glycerol stock culture, which were cultivated at $37^{\circ} \mathrm{C}$ until they reach optical density of 1.000 at $\lambda=600 \mathrm{~nm}$ [11]. 


\subsection{Determination of the optical density of the bacterial cultures}

The optical density was determined by using a microplate reader Spectrostar Nano (BMG Labtech, Germany) against MRS broth as blank at $\lambda=600 \mathrm{~nm}$. The sample volume was $200 \mu \mathrm{l}$ with correction to $1 \mathrm{~cm}$ path length. Every value is presented as the mean of nine measurements (three samples, measured three consecutive times each) [12].

\subsection{Determination of the minimal inhibitory concentrations of antibiotics and preservatives}

MRS broth samples $(850 \mu \mathrm{l})$ with double-fold decreasing concentrations of antibiotic/ preservative erythromycin (Merck, Germany) 0.38 - $200 \mu \mathrm{g} / \mathrm{ml}$, lincomycin (Merck, Germany) 0.38 - $100 \mu \mathrm{g} / \mathrm{ml}$, ciprofloxacin (Merck, Germany) 0.38 - $100 \mu \mathrm{g} / \mathrm{ml}$, penicillin G (Merck, Germany) 0.38 - $100 \mu \mathrm{g} / \mathrm{ml}$, tetracycline (Merck, Germany) 0.38 - $200 \mu \mathrm{g} / \mathrm{ml}$, benzoic acid (Merck, Germany) $0.25-8 \mathrm{mg} / \mathrm{ml}$, and sorbic acid (Merck, Germany) $0.125-8 \mathrm{mg} / \mathrm{ml}$ were inoculated with $50 \mu$ active bacterial culture and cultivated at $37^{\circ} \mathrm{C}$ for $24 \mathrm{~h}$. The optical density at $\lambda=$ $600 \mathrm{~nm}$ was determined for each sample.

\section{Results and discussion}

The effect of sublethal concentrations of 5 antibiotics and 2 preservatives was studied during $24 \mathrm{~h}$ cultivation and the minimal inhibitory concentrations (MICs) were determined for all antimicrobials.

Lactobacillus bulgaricus S6 was sensitive towards all antibiotics, except ciprofloxacin (Fig. 1 - Fig. 5) of the effective antibiotics the highest MIC was determined for erythromycin $-3.06 \mu \mathrm{g} / \mathrm{ml}$.

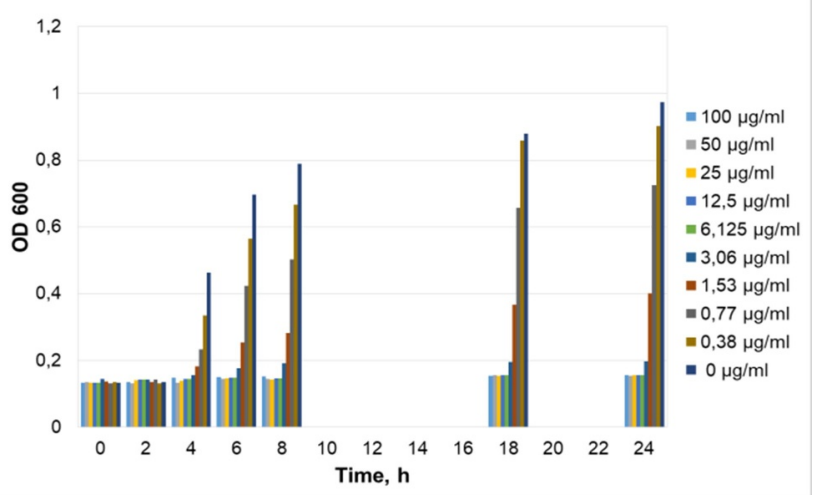

Fig. 1. Effect of sublethal concentration of erythromycin on the growth and development of Lactobacillus bulgaricus S6

All of the tested lincomycin concentrations inhibited the growth of Lactobacillus bulgaricus S6 (Fig. 2). The actual MIC for this antibiotic was below $0.38 \mu \mathrm{g} / \mathrm{ml}$.

The strain exhibited resistance towards all of the ciprofloxacin concentrations included in the experiment (Fig. 3).

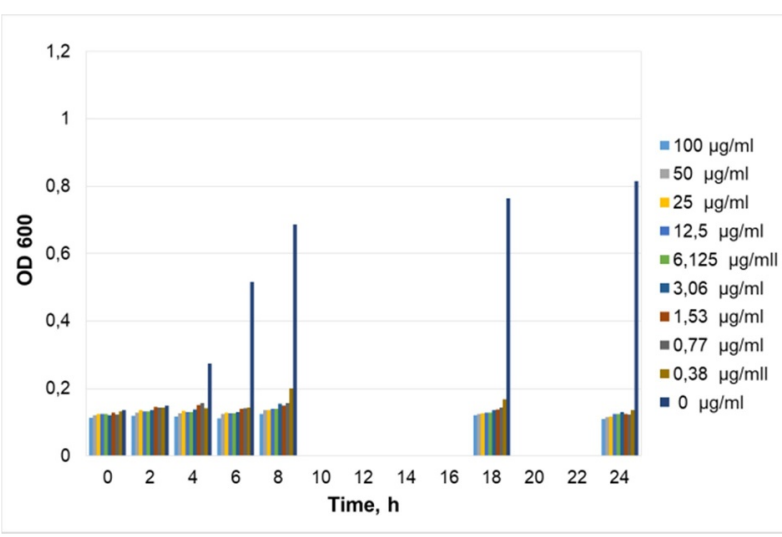

Fig. 2. Effect of sublethal concentration of lincomycin on the growth and development of Lactobacillus bulgaricus S6

This was the only antibiotic, which did not influence the development of Lactobacillus bulgaricus S6 even in $100 \mu \mathrm{g} / \mathrm{ml}$ concentration.

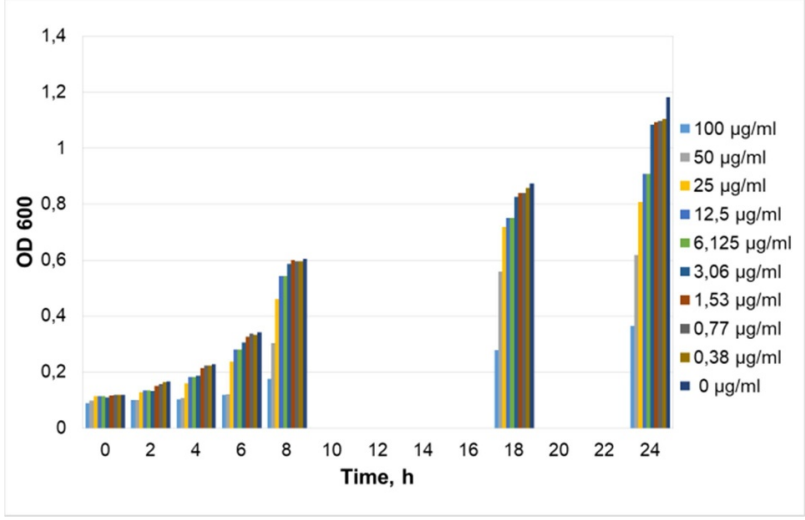

Fig. 3. Effect of sublethal concentration of ciprofloxacin on the growth and development of Lactobacillus bulgaricus S6

The other antimicrobial, which inhibited the growth of Lactobacillus bulgaricus S6 completely, was penicillin $\mathrm{G}$ (Fig. 4). The exact MIC was below $0.38 \mu \mathrm{g} / \mathrm{ml}$.

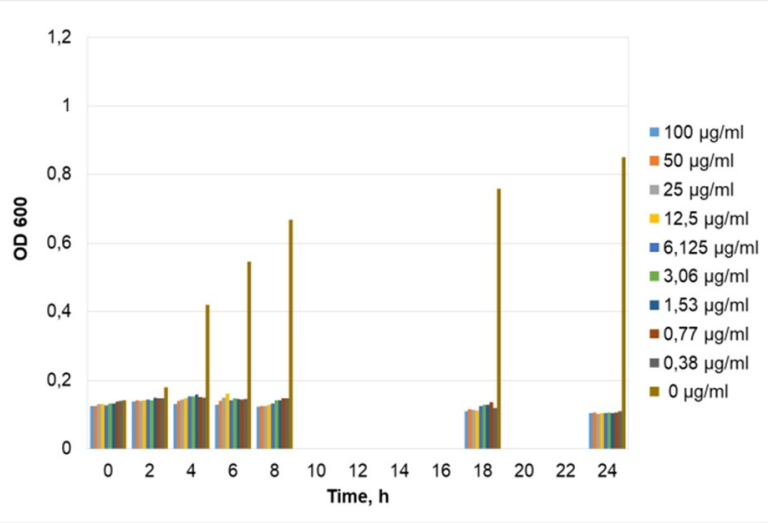

Fig. 4. Effect of sublethal concentration of penicillin $\mathrm{G}$ on the growth and development of Lactobacillus bulgaricus S6

Lactobacillus bulgaricus S6 was more sensitive towards tetracycline in comparison with erythromycin. The MIC was $1.53 \mu \mathrm{g} / \mathrm{ml}$ (Fig. 2). 


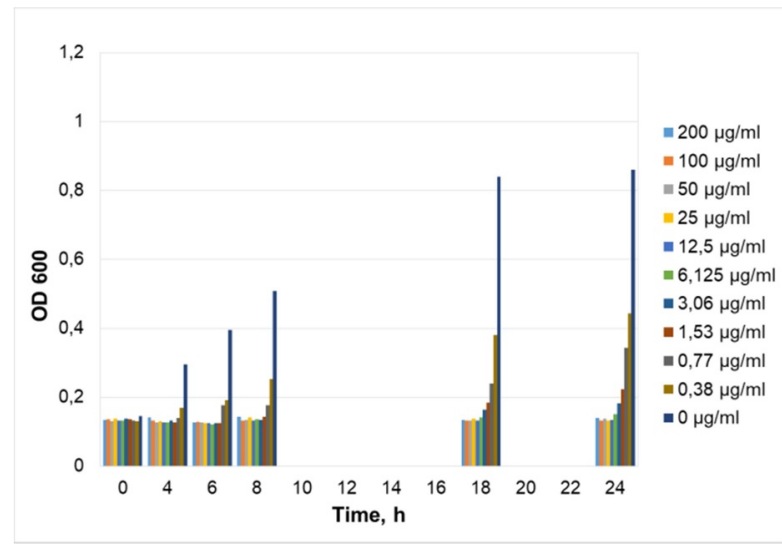

Fig. 5. Effect of sublethal concentration of tetracycline on the growth and development of Lactobacillus bulgaricus S6

On the other hand, it was resistant to benzoic and sorbic acids (Fig. 6 and Fig. 7). The MIC of both preservatives was $8 \mathrm{mg} / \mathrm{ml}$.

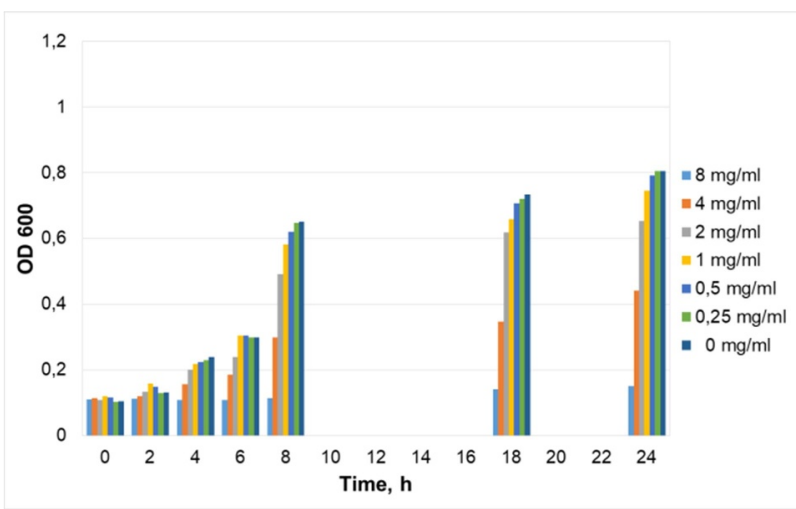

Fig. 6. Effect of sublethal concentration of benzoic acid on the growth and development of Lactobacillus bulgaricus S6

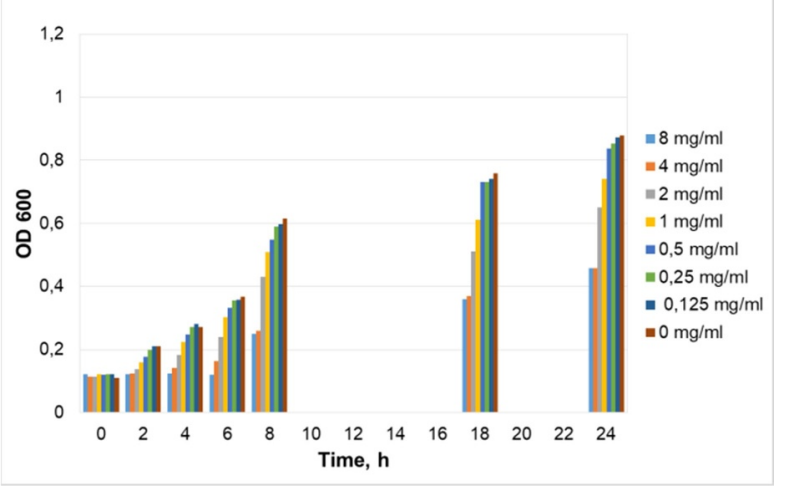

Fig. 7. Effect of sublethal concentration of sorbic acid on the growth and development of Lactobacillus bulgaricus S6

The MICs of all antimicrobials for every Lactobacillus strain, included in this study, are presented in Table 1. Since some compounds showed the same MICs for multiple strains, Table 1 also includes the optical density of the microbial suspension at sublethal concentrations (OD at $0.5 \mathrm{MIC}$ ). This gave us better understanding of the effect of the antibiotics and preservatives in the development of the lactobacilli.

All strains were susceptible to the activity of penicillin $G$ in all tested concentrations, which was reported in multiple studies in reference literature [9, 13]. All eight lactobacilli were resistant towards ciprofloxacin in the tested concentrations. This result is supported by the work of other authors, according to which most Lactobacillus species are resistant to inhibitors of the nucleic acid synthesis, such as ciprofloxacin, nalidixic acid and metronidazole [13].

Strain and species specific differences in the effect of the rest of the antibiotics were observed. Lactobacillus acidophilus $\mathrm{S} 11$ was most resistant towards tetracycline with MIC of $6.125 \mu \mathrm{g} / \mathrm{ml}$ and was most sensitive to lincomycin (MIC $0.77 \mu \mathrm{g} / \mathrm{ml}$ ). Sharma et al. also report resistance to tetracycline for 7 Lactobacillus acidophilus strains [14]. Lactobacillus bulgaricus $\mathrm{S} 2$ showed the exact same response to the influence of these antibiotics, while Lactobacillus bulgaricus S4 was a little more sensitive towards tetracycline and the MIC for this strain was 3.06 $\mu \mathrm{g} / \mathrm{ml}$.

Lactobacillus bulgaricus S19 exhibited its highest resistance towards erythromycin, which had MIC of 3.06 $\mu \mathrm{g} / \mathrm{ml}$. On the other hand, Lactobacillus bulgaricus S28 was equally sensitive towards tetracycline and erythromycin with MIC for both antibiotics $1.53 \mu \mathrm{g} / \mathrm{ml}$.

Lactobacillus gasseri S20 demonstrated the highest tolerance towards the tested antimicrobials. The MICs of erythromycin and lincomycin was $12.5 \mu \mathrm{g} / \mathrm{ml}$ and for tetracycline $-6.25 \mu \mathrm{g} / \mathrm{ml}$. In contrast, L. helveticus S3 was one of the more sensitive strains. The highest MIC of $3.06 \mu \mathrm{g} / \mathrm{ml}$ was observed for erythromycin.

The prevailing resistance overall for the tested strains was towards tetracycline and erythromycin, which is in compliance with the results of other studies on the antimicrobial resistance of Lactobacillus strains [15-20]. For the rest of the antibiotics, included in the study, various sensitivities were reported in the reference literature. This could be due to the facts that the mechanisms of resistance could be both intrinsic and acquired [9].

There were two distinct groups in regard to the effect of the preservatives on the growth and development of the lactobacilli. The first group, including Lactobacillus bulgaricus S6. Lactobacillus bulgaricus S19. Lactobacillus bulgaricus S28 and Lactobacillus gasseri S20. exhibited better tolerance towards both benzoic and sorbic acid. The detected MIC was $8 \mathrm{mg} / \mathrm{ml}$ for benzoic acid and above $8 \mathrm{mg} / \mathrm{ml}$ for sorbic acid. The rest of the tested strains were more sensitive and the MIC of both antimicrobials for this group was $4 \mathrm{mg} / \mathrm{ml}$. Despite this fact, all MICs for the preservatives were above the allowed concentration in food according to the EU regulations, which is up to $2 \mathrm{mg} / \mathrm{ml}$. 
Table 1. Effect of sublethal concentrations of antibiotics and preservatives on the growth and development of the Lactobacillus strains

\begin{tabular}{|c|c|c|c|c|c|c|c|c|c|c|}
\hline \multicolumn{3}{|c|}{ Strains } & 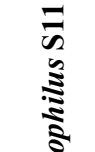 & 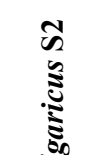 & 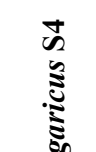 & 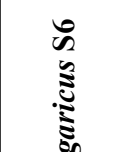 & 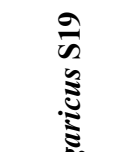 & 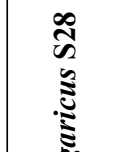 & 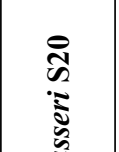 & $\begin{array}{l}\mathscr{n} \\
\tilde{\Xi} \\
\tilde{\Xi}\end{array}$ \\
\hline \multirow{10}{*}{ 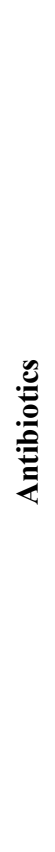 } & \multirow{2}{*}{ erythromycin } & $\mathrm{MIC}, \mu \mathrm{g} / \mathrm{ml}$ & 1.53 & 1.53 & 1.53 & 3.06 & 3.06 & 1.3 & 12.5 & 3.06 \\
\hline & & OD at $0.5 \mathrm{MIC}$ & 0.190 & 0.362 & 0.270 & 0.400 & 0.356 & 0.595 & 0.729 & 0.265 \\
\hline & \multirow{2}{*}{ lincomycin } & $\mathrm{MIC}, \mu \mathrm{g} / \mathrm{ml}$ & 0.77 & 0.77 & 0.77 & $<0.38$ & $<0.38$ & 0.77 & 12.5 & 0.77 \\
\hline & & OD at $0.5 \mathrm{MIC}$ & 0.616 & 0.668 & 0.648 & - & - & 0.545 & 0.791 & 0.125 \\
\hline & \multirow{2}{*}{ ciprofloxacin } & $\mathrm{MIC}, \mu \mathrm{g} / \mathrm{ml}$ & 100 & 100 & 100 & over 100 & over 100 & over 100 & over 100 & 100 \\
\hline & & OD at $0.5 \mathrm{MIC}$ & 0.437 & 0.439 & 0.488 & 0.620 & 0.549 & 0.477 & 1.030 & 0.553 \\
\hline & \multirow{2}{*}{ penicillin G } & $\mathrm{MIC}, \mu \mathrm{g} / \mathrm{ml}$ & $<0.38$ & $<0.38$ & $<0.38$ & $<0.38$ & $<0.38$ & $<0.38$ & $<0.38$ & $<0.38$ \\
\hline & & OD at $0.5 \mathrm{MIC}$ & - & - & - & - & - & - & - & - \\
\hline & \multirow{2}{*}{ tetracycline } & $\mathrm{MIC}, \mu \mathrm{g} / \mathrm{ml}$ & 6.125 & 6.125 & 3.06 & 1.53 & 1.53 & 1.53 & 6.125 & 1.53 \\
\hline & & $\mathrm{OD}$ at $0.5 \mathrm{MIC}$ & 0.450 & 0.487 & 0.319 & 0.343 & 0.333 & 0.351 & 0.596 & 0.408 \\
\hline \multirow{4}{*}{ 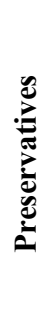 } & \multirow{2}{*}{ benzoic acid } & $\mathrm{MIC}, \mathrm{mg} / \mathrm{ml}$ & 4 & 4 & 4 & 8 & 8 & 8 & 8 & 4 \\
\hline & & $\mathrm{OD}$ at $0.5 \mathrm{MIC}$ & 0.263 & 0.230 & 0.235 & 0.441 & 0.520 & 0.447 & 0.588 & 0.267 \\
\hline & \multirow{2}{*}{ sorbic acid } & $\mathrm{MIC}, \mathrm{mg} / \mathrm{ml}$ & 4 & 4 & 4 & over 8 & over 8 & over 8 & over 8 & 4 \\
\hline & & OD at $0.5 \mathrm{MIC}$ & 0.365 & 0.322 & 0.342 & 0.458 & 0.420 & 0.459 & 0.567 & 0.352 \\
\hline
\end{tabular}

\section{Conclusion}

The study on the effect of five antibiotics and two preservatives on lactobacilli with probiotic properties showed that based on the obtained data the eight strains could be divided into two groups - more resistant strains and more sensitive towards the antimicrobials.

The first group includes Lactobacillus bulgaricus S2. Lactobacillus bulgaricus S4. Lactobacillus bulgaricus S19 and Lactobacillus gasseri S20. The most resistant of this group was Lactobacillus gasseri S20. The second group showed more sensitivity and the most affected by the antimicrobials was Lactobacillus bulgaricus $\mathrm{S} 28$.

Unlike the effects of penicillin $\mathrm{G}$ and ciprofloxacin, which are well established for the entire genus Lactobacillus, most other antimicrobials affect different species and even strains to a different extent. This variation in resistance necessitates the investigation of each strain before its application.
Acknowledgements: This work was supported by the Bulgarian Ministry of Education and Science under the National Research Programme "Healthy Foods for a Strong Bio-Economy and Quality of Life" approved by DCM \# 577 /17.08.2018.

\section{References}

1. M. Kechagia, D. Basoulis, S. Konstantopoulou, D. Dimitriadi, K. Gyftopoulou, N. Skarmoutsou, E. M. Fakiri, ISRN Nutr. 2013, 481651 (2013)

2. M. Surendran Nair, M.A. Amalaradjou, K. Venkitanarayanan, Adv. Appl. Microbiol. 98, 1-29 (2017)

3. R. Nagpal, A. Kumar, M. Kumar, P.V. Behare, S. Jain, H. Yadav, FEMS Microbiol. Lett. 334, 1-15 (2012) 
4. V.N. Kalpana, V. Devi Rajeswari, Preservatives and preservation approaches in beverages (Academic Press, Elsevier, Cambridge, MA, 2019)

5. T. Shibamoto, L.F. Bjeldanes, Food science and technology, introduction to food toxicology (Academic Press, Elsevier, Cambridge, MA, 1993)

6. F.M. Treiber, H. Beranek-Knauer, Antibiotics. 10, 534 (2021)

7. V. Ojetti, G. Gigante, M.E. Ainora, F. Fiore, F. Barbaro, A. Gasbarrini, Dig. Liver Dis. Suppl. 3, 3539 (2009)

8. K. Wang, H. Zhang, J. Feng, L. Ma, C. de la FuenteNúñez, S. Wang, X. Lu, J. Agric. Food Res. 1, 100006 (2019)

9. M. Gueimonde, B. Sánchez, C. de los ReyesGavilán, A. Margolles, Front. Microbiol. 4, 202 (2013)

10. S. Gazzola, C. Fontana, D. Bassi, P. Cocconcelli, Food Microbiol. 30, 348-354 (2012)

11. A. Slavchev, Z. Kovacs, H. Koshiba, A. Nagai, G. Bázár, A. Karstanov, Y. Kubota, R. Tsenkova, PLoS One. 10, e0130698 (2015)

12. A. Slavchev, Z. Kovacs, H. Koshiba, G. Bázár, B. Pollner, A. Krastanov, R. Tsenkova, J. Near Infrared Spectrosc. 25, 423-431 (2017)

13. H. Abriouel, M.C.C. Muñoz, L.L. Lerma, B.P. Montoro, W. Bockelmann, R. Pichner, J. Kabisch, G.S. Cho, C.M.A.P. Franz, A. Gálvez, N. Benomar, Food Res. Int., 78, 465-481 (2015)

14. P. Sharma, S.K. Tomar, V. Sangwan, P. Goswami, R. Singh, J. Food Saf, 36, 38-51 (2016)

15. M. S. Ammor, M. Gueimonde, M. Danielsen, , M. Zagorec, A.H. van Hoek, C. G. de Los ReyesGavilan, B. Mayo, A. Margolles. Appl. Environ. Microbiol. 74, 1394-1401(2008)

16. D. Zonenschain, A. Rebecchi, L. Morelli, J. Appl. Microbiol. 107, 1559-1568 (2009)

17. L. I. Ouoba, V. Lei, L. B. Jensen, Int. J. Food Microbiol. 121, 217-224. (2008)

18. N. Zhou, J. X. Zhang, M. T. Fan, J. Wang, G. Guo, X. Y. Wei, J. Dairy Sci. 95, 4775-4783 (2012)

19. G. Huys, K. D"Haene, M. Danielsen, J. Matto, M. Egervarn, P. Vandamme, J. Food Prot. 71, 339-344 (2008)

20. M. Nawaz, J. Wang, A. Zhou, C. Ma, X. Wu, J. E. Moore, B. C. Millar, J. Xu, Curr. Microbiol. 62, 1081-1089 (2011) 